\title{
Regional wall motion abnormality at the lateral wall disturbs correlations between tissue Doppler E/e' ratios and left ventricular diastolic performance parameters measured by invasive methods
}

\author{
Toshiharu Fujii • Koichiro Yoshioka • Masataka Nakano • Gaku Nakazawa • \\ Mari Amino • Naoki Masuda • Norihiko Shinozaki • Shigetaka Kanda • \\ Nobuhiko Ogata $\cdot$ Yoshiaki Deguchi $\cdot$ Fuminobu Yoshimachi $\cdot$ Yuji Ikari
}

Received: 24 July 2013/Revised: 23 August 2013/Accepted: 1 September 2013/Published online: 26 September 2013

(C) The Author(s) 2013. This article is published with open access at Springerlink.com

\begin{abstract}
Background The impact of regional wall motion abnormality (RWMA) on the accuracy of heart failure with preserved ejection fraction (HFpEF) diagnosis using the $\mathrm{E} / \mathrm{e}^{\prime}$ ratio, which is a non-invasive parameter of left ventricular diastolic performance, is unknown. The purpose of this study was to elucidate the impact of RWMA of the lateral wall (RWMAlat) on the correlation between E/ $\mathrm{e}^{\prime}$ and invasive parameters of left ventricular diastolic performance.

Methods Three hundred and eight consecutive patients undergoing tissue Doppler imaging and catheterization pressure examination were retrospectively analyzed. E/ $\mathrm{e}^{\prime}$ was calculated as the ratio of early diastolic transmitral flow velocity to mitral annular velocity at the lateral wall. Invasive parameters including left ventricular end-diastolic pressure (LVEDP) and isovolumetric relaxation time constant $(\tau)$ were assessed based on the left ventricular pressure study. Correlation coefficients between $\mathrm{E} / \mathrm{e}^{\prime}$ and these invasive parameters were analyzed and compared between cases with RWMAlat and without RWMA.

Results LVEDP and $\tau$ correlated well with E/e' for all 308 patients ( $r=0.51$ and $r=0.65$, respectively). Sixtytwo patients had RWMA; the remaining 246 did not have RWMAlat. We confirmed that the presence of RWMAlat weakens both the correlations between E/ $\mathrm{e}^{\prime}$ and LVEDP $(r=0.574$ vs. $r=0.381)$, and $\mathrm{E} / \mathrm{e}^{\prime}$ and $\tau(r=0.729$ vs. $r=0.461)$.
\end{abstract}

T. Fujii $\cdot$ K. Yoshioka $\cdot$ M. Nakano $\cdot$ G. Nakazawa $\cdot$ M. Amino · N. Masuda · N. Shinozaki · S. Kanda · N. Ogata · Y. Deguchi · F. Yoshimachi · Y. Ikari $(\bowtie)$

Department of Cardiology, Tokai University School of

Medicine, 143 Shimokasuya, Isehara 259-1193, Japan

e-mail: ikari@is.icc.u-tokai.ac.jp
Conclusions Although E/e' correlates well with parameters of left ventricular diastolic performance assessed by invasive methods, the presence of RWMAlat worsens this correlation. In cases with RWMAlat, careful assessment is required for $\mathrm{HFpEF}$ diagnosis because the diagnostic value of the E/e' ratio could be decreased compared to patients without RWMAlat.

Keywords Heart failure with normal left ventricular ejection fraction - Diastolic phase of mitral annulus velocity $\cdot \mathrm{E} / \mathrm{e}^{\prime} \cdot$ Isovolumetric relaxation time constant - Left ventricular enddiastolic pressure - Tissue Doppler imaging

\section{Introduction}

The precise understanding of clinical situations of diastolic heart failure has proven difficult because the diagnostic criteria have not been standardized [1-6]. Recent reports showed that heart failure with preserved ejection fraction (HFpEF) accounts for nearly half of all heart failure cases [7-9]. These reports impressed upon us the need for a noninvasive parameter that reflects left ventricular diastolic performance for standardized diagnostic criteria of HFpEF.

The E/e' ratio, which is obtained by measurement of the early diastolic transmitral flow velocity (E) and the mitral annular velocity at the early diastolic phase on tissue Doppler $\left(\mathrm{e}^{\prime}\right)$, was reported to be a good index for estimating the left ventricular filling pressure [10-15]. E/e' correlates well with parameters assessed by invasive techniques, such as left ventricular diastolic pressure (LVEDP), which is an important indicator of diastolic dysfunction, or the isovolumetric relaxation time constant $(\tau)$, which is a parameter reflecting left ventricular 
relaxation [16-20]. Therefore, the $E / \mathrm{e}^{\prime}$ ratio is one of the most important diagnostic parameters used by many working groups [6, 21-23].

However, the specificity of E/e' measurements, based on assessing a spot on the lateral or septal wall, is influenced by factors that can reduce the strength of the correlation between the results of invasive versus non-invasive techniques [17, 24]. In particular, we hypothesized that regional wall motion abnormality (RWMA) on echocardiography contributes to this, which may be problematic when diagnosing HFpEF using tissue Doppler imaging (TDI) in clinical practice.

To study the effect of RWMA at the lateral wall (RWMAlat) on correlations between $\mathrm{E} / \mathrm{e}^{\prime}$ values measured at the lateral wall (E/e'lat) and parameters assessed by invasive techniques (LVEDP and $\tau$ ), we performed correlation analysis and compared correlation coefficients in patients with or without RWMAlat.

\section{Materials and methods}

\section{Study population}

We retrospectively studied the medical records of 308 patients who underwent coronary angiography and left ventricular pressure examination from April 2009 to April 2010 at Tokai University School of Medicine because of suspicion of coronary artery disease or for the evaluation of global cardiac function. These patients had undergone echocardiography and blood testing 2 months prior to the catheterization study. All patients gave written informed consent; this study was designed in accordance with the ethical standards of the General Clinical Research Center of Tokai University School of Medicine.

Exclusion criteria were as follows: low left ventricular ejection fraction (LVEF) below $30 \%$, abnormal sinus rhythm (atrial fibrillation, atrial flutter, and frequent premature beat), waveform abnormalities (bundle branch block, pacing rhythm), severe mitral annular calcification, and decompensated heart failure in the acute phase.

\section{Study protocols}

To study the impact of RWMAlat on the correlation between $\mathrm{E} / \mathrm{e}^{\prime}$ lat values and parameters assessed by invasive techniques, we performed the two following analyses:

(1) A correlation between $\mathrm{E} / \mathrm{e}^{\prime}$ lat and invasive parameters To confirm the correlation between E/e'lat and invasive parameters for all 308 patients, we applied Pearson's correlation coefficient testing. Invasive parameters also included systolic aortic pressure (AoSP), diastolic aortic pressure (AoDP), maximum rate of left ventricular pressure rise (positive $\mathrm{d} p / \mathrm{d} t$ ), and peak rate of fall in left ventricular pressure (negative $\mathrm{d} p / \mathrm{d} t$ ) in addition to LVEDP and $\tau$.

(2) Impact of RWMAlat on the correlation between $\mathrm{E} / \mathrm{e}^{\prime}$ and invasive parameters

To confirm the impact of RWMAlat on the correlation between E/e'lat and invasive parameters (LVEDP and $\tau$ ), the correlation coefficients between $E / \mathrm{e}^{\prime}$ and these parameters were compared in patients with RWMAlat and those without RWMA on echocardiographic assessment.

\section{Echocardiography}

All echocardiographic studies were performed in the supine position using Xario XG with a $1.8-4.2-\mathrm{MHz}$ PST-25AT transducer (Toshiba Medical Systems Corporation, Tochigi, Japan) by an experienced investigator. Comprehensive echocardiographic examination consisted of conventional 2-dimensional, Doppler, and color flow imaging, and TDI.

Conventional measurements (2-dimensional, M-mode, pulsed Doppler, color flow imaging)

The recorded echocardiographic data were evaluated and assessed based on the recommendations of the American Society of Echocardiography [25].

For 2-dimensional measurements, the LVEF was calculated in apical 4-chamber and apical 2-chamber views at end-diastole and at end-systole by modified Simpson's rule $[25,26]$. Papillary muscles were excluded from the cavity in the tracking. End-diastole was defined at the onset of the QRS wave on electrocardiographic monitoring, and endsystole was defined as the time of the frame preceding mitral valve opening.

Regional left ventricular function was assessed by a 17-segment model recommended by the American Society of Echocardiography in a parasternal long-axis, 2-chamber, and 4-chamber orientation, and 3 different levels in shortaxis orientation [25]. RWMA was classified into 5 categories according to regional left ventricular function as follows: "normal", "hypokinesis", "akinesis", "dyskinesis", and "aneurysmal". RWMAs were divided into 3 categories by their location, i.e., (1) anterior, antero-septal, or apical cap, (2) inferior, and (3) lateral, infero-lateral, or antero-lateral. These 3 categories were designated the "antero-septal area", "inferior area", and "lateral area", respectively. Therefore, the RWMAlat was defined as hypokinesis, akinesis, dyskinesis, or aneurysmal in lateral, infero-lateral, or antero-lateral areas.

In M-mode recording, septal wall thickness, posterior wall thickness, and left ventricular internal dimensions 
were measured over several cardiac cycles in the parasternal short-axis acoustic window to optimize mediallateral beam orientation. These parameters were measured at the level of the mitral valve leaflet tips at the left ventricular minor axis. The measurements were confirmed by the 2-dimensional method. The thickness of the ventricular wall and chamber size were measured as the distance between the leading edge echoes.

In pulsed-wave Doppler echocardiography, the left ventricular inflow velocity pattern, which consists of early diastolic velocity (E) and late diastolic velocity (A), was recorded while the sample volume was placed at the tip of anterior and posterior mitral leaflets.

In color flow imaging, the severity of valve regurgitation was evaluated based on the recommendations of the American Society of Echocardiography [27, 28]. Regurgitation severity was classified into 3 grades: mild, moderate, and severe, based on the American College of Cardiology/American Heart Association Task Force on Practice Guidelines [29].

\section{Tissue Doppler imaging}

TDI of the mitral annulus velocity was obtained from the apical 4-chamber view, while a 5- to 10 -mm sample volume was placed at the lateral mitral annulus. The diastolic phase of the mitral annulus velocity consists of the early diastolic phase $\left(\mathrm{e}^{\prime}\right)$ and the late diastolic phase $\left(\mathrm{a}^{\prime}\right)$ as the left ventricular inflow velocity pattern in pulsed-wave Doppler echocardiography. Here, $\mathrm{e}^{\prime}$ was expressed as E/e by calculating the ratio of $E$ to $e^{\prime}$.

Coronary angiography and left ventricular pressure investigations

For coronary angiography and left ventricular pressure assessment, a suitable catheter was inserted via either the femoral or radial artery. Coronary angiography was performed by a $4 \mathrm{Fr}$ coronary catheter, which was selected to fit each patient's coronary arteries, and lesions were evaluated based on the American Heart Association classification [30]. Left ventricular pressure was measured using a 4Fr fluid-filled pigtail catheter. All pressure data were measured and analyzed by an RMC-3000 instrument (Nihon Kohden, Tokyo, Japan). LVEDP, positive $\mathrm{d} p / \mathrm{d} t$, negative $\mathrm{d} p / \mathrm{d} t$, and $\tau$ were measured. Positive $\mathrm{d} p / \mathrm{d} t$ and negative $\mathrm{d} p / \mathrm{d} t$ were defined as the maximum and minimum differential values calculated from the following formula:

$($ Positive $/$ negative $) \mathrm{dp} / \mathrm{dt}=\frac{[\mathrm{P}(\mathrm{n})-\mathrm{P}(\mathrm{n}-1)]}{\text { Sample rate }}$

$\tau$ was derived from the slope of the graph $(-1 / \tau)$ plotted as a natural logarithm of the pressure scale on the $y$-axis and time scale on the $x$-axis, which was described by the following mono-exponential equation [31-36]:

$P_{(\mathrm{t})}=P_{0} e^{\frac{\mathrm{t}}{\mathrm{P} \tau}}+P_{\infty}$

where $t$ is the time from negative $\mathrm{d} p / \mathrm{d} t, P_{0}$ the monoexponential amplitude coefficient, $P_{\tau}$ the mono-exponential time constant, and $P_{\infty}$ is the mono-exponential asymptotic equation.

AoDP and AoSP were also measured after pulling out the catheter from the left ventricle to the ascending aorta. LVEDP, AoDP, and AoDP were recorded as average values of measurements over $3 \mathrm{~s}$. All measurements were recorded while the patients were holding their breath in end-expiratory cycle.

Statistical analysis

All data are presented as the mean \pm standard deviation (SD). Pearson's correlation coefficient analysis and simple regression were used to assess the associations between invasive or non-invasive measurements. $P<0.05$ was considered statistically significant. All statistical calculations were performed using JMP version 9 (SAS Institute, Inc., Cary, North Carolina, USA).

\section{Results}

To study the impact of RWMAlat on the correlation between $E / \mathrm{e}^{\prime}$ lat values and parameters assessed by invasive methods (LVEDP and $\tau$ ), we compared this correlation coefficient in patients with or without RWMAlat. Ninetytwo patients were excluded according to exclusion criteria (30 patients of low LVEF below 30\%, 9 patients of abnormal sinus rhythm, 34 patients of waveform abnormalities, 12 patients severe mitral annular calcification, and 7 patients of decompensated heart failure), and three hundred and eight patients were analyzed in the present study. The baseline characteristics for all 308 enrolled patients are shown in Table 1 . The mean age was $64.1 \pm 10.9$ years and $82.6 \%$ were male. Table 2 shows the echocardiographic findings. The mean E/e'lat was $12.4 \pm 4.4$. Fiftynine percent $(n=183)$ showed no RWMA, and are regarded as controls for the $41 \%(n=125)$ who had RWMA at either area. Among these patients with RWMA, $50 \%(n=62)$ had RWMAlat. Table 3 shows the results of the catheterization study. The mean LVEDP and $\tau$ were $1.4 \pm 24.9 \mathrm{mmHg}$ and $40.1 \pm 19.1 \mathrm{~ms}$, respectively.

Correlations between E/e'lat and invasive parameters

To confirm the correlations between E/e'lat and invasive parameters (LVEDP, AoSP, AoDP, positive $\mathrm{d} p / \mathrm{d} t$, negative 
Table 1 Baseline patient characteristics $(n=308)$

\begin{tabular}{|c|c|}
\hline Age (years) & $64.1 \pm 10.9$ \\
\hline Male (\%) & $82.8(n=255)$ \\
\hline Height (cm) & $162.5 \pm 9.04$ \\
\hline Weight (kg) & $62.9 \pm 11.5$ \\
\hline Body surface area $\left(\mathrm{m}^{2}\right)$ & $1.67 \pm 0.18$ \\
\hline Serum creatinine $(\mathrm{mg} / \mathrm{dl})$ & $1.45 \pm 1.89$ \\
\hline Estimated GFR (ml/min) & $61.1 \pm 23.1$ \\
\hline BNP (pg/ml) & $96.9 \pm 182.5$ \\
\hline Hemodialysis (\%) & $7.5(n=23)$ \\
\hline Diabetes mellitus (\%) & $36.4(n=112)$ \\
\hline Untreated & $8.1(n=25)$ \\
\hline Oral medication & $16.9(n=52)$ \\
\hline Insulin & $11.4(n=35)$ \\
\hline Current smoker $(\%)$ & $48.1(n=148)$ \\
\hline Hypertension (\%) & $74.7(n=230)$ \\
\hline Dyslipidemia (\%) & $65.6(n=202)$ \\
\hline Total cholesterol (mg/dl) & $178.3 \pm 41.3$ \\
\hline HDL cholesterol (mg/dl) & $56.4 \pm 18.1$ \\
\hline Triglyceride (mg/dl) & $144.4 \pm 135.9$ \\
\hline Prior CVD (\%) & $10.4(n=32)$ \\
\hline Prior heart failure $(\%)$ & $10.4(n=32)$ \\
\hline Prior ischemic heart disease $(\%)$ & $60.1(n=185)$ \\
\hline Prior AP & $17.2(n=53)$ \\
\hline Prior UA & $7.5(n=23)$ \\
\hline Prior MI & $35.4(n=109)$ \\
\hline Dilated cardiomyopathy (\%) & $1.9(n=6)$ \\
\hline Hypertrophic cardiomyopathy (\%) & $2.6(n=8)$ \\
\hline Vasospastic angina $(\%)$ & $4.2(n=13)$ \\
\hline Idiopathic ventricular fibrillation (\%) & $0.6(n=2)$ \\
\hline
\end{tabular}

$B N P$ brain natriuretic peptide, $C V D$ cerebrovascular disease, $A P$ angina pectoris, $U A$ unstable angina, $M I$ myocardial infarction

$\mathrm{d} p / \mathrm{d} t$, and $\tau$ ), we analyzed the data for all 308 patients (Fig. 1). LVEDP and $\tau$ correlated well with E/e'lat ( $r=0.51 ; P<0.001$, and $r=0.65 ; P<0.001$, respectively), but the other parameters tested (AoDP, AoSP, positive $\mathrm{d} p / \mathrm{d} t$, and negative $\mathrm{d} p / \mathrm{d} t)$ correlated poorly. Moreover, $\mathrm{e}^{\prime}$ correlated well with $\tau(r=0.46 ; P<0.001)$.

Impact of RWMAlat on the correlation between E/e'lat and invasive parameters

To investigate whether RWMAlat affected the good correlation between E/e'lat and LVEDP and $\tau$, we compared 62 patients with RWMAlat and 183 controls patients without RWMA (Fig. 2). The results show that the correlation coefficients were low in the group with RWMAlat for both LVEDP and $\tau$ (left panel; $r=0.574$ vs. $r=0.381$, right panel; $r=0.729$ vs. $r=0.461$, respectively). Thus, it was confirmed that RWMAlat weakens the correlation
Table 2 Echocardiographic findings

\begin{tabular}{|c|c|}
\hline LVEF $(\%)$ & $62.6 \pm 12.6$ \\
\hline IVS-WT (mm) & $11.1 \pm 2.1$ \\
\hline PWT (mm) & $10.3 \pm 1.9$ \\
\hline LVDd (mm) & $50.2 \pm 7.0$ \\
\hline LVDs (mm) & $31.7 \pm 8.0$ \\
\hline $\mathrm{E}(\mathrm{cm} / \mathrm{s})$ & $56.4 \pm 18.4$ \\
\hline $\mathrm{A}(\mathrm{cm} / \mathrm{s})$ & $70.4 \pm 18.8$ \\
\hline $\mathrm{E} / \mathrm{A}$ & $0.8 \pm 0.3$ \\
\hline $\mathrm{e}^{\prime}(\mathrm{cm} / \mathrm{s})$ & $5.1 \pm 2.2$ \\
\hline $\mathrm{E} / \mathrm{e}^{\prime}$ & $12.4 \pm 4.4$ \\
\hline \multicolumn{2}{|c|}{ Mitral regurgitation (\%) } \\
\hline Mild & $41.6(n=128)$ \\
\hline Moderate & $9.1(n=28)$ \\
\hline Severe & $0.3(n=1)$ \\
\hline \multicolumn{2}{|c|}{ Aortic regurgitation (\%) } \\
\hline Mild & $20.8(n=64)$ \\
\hline Moderate & $5.8(n=18)$ \\
\hline Severe & $1.3(n=4)$ \\
\hline \multicolumn{2}{|c|}{ Tricuspid regurgitation (\%) } \\
\hline Mild & $34.4(n=106)$ \\
\hline Moderate & $3.6(n=11)$ \\
\hline Severe & $0.6(n=2)$ \\
\hline \multicolumn{2}{|c|}{ Pulmonary regurgitation (\%) } \\
\hline Mild & $27.6(n=85)$ \\
\hline Moderate & $1.3(n=4)$ \\
\hline Severe & $0.3(n=1)$ \\
\hline \multicolumn{2}{|c|}{ Aortic stenosis $(\%)$} \\
\hline Mild & $3.2(n=10)$ \\
\hline Moderate & $1.6(n=5)$ \\
\hline Severe & $0.3(n=1)$ \\
\hline \multicolumn{2}{|c|}{ Mitral stenosis (\%) } \\
\hline Mild & $0.3(n=1)$ \\
\hline Moderate & 0 \\
\hline Severe & 0 \\
\hline \multicolumn{2}{|c|}{ RWMA at antero-septal area (\%) } \\
\hline Hypokinesis & $18.5(n=57)$ \\
\hline Akinesis & $2.2(n=7)$ \\
\hline Dyskinesis & $2.3(n=10)$ \\
\hline Aneurysmal & 0 \\
\hline \multicolumn{2}{|c|}{ RWMA at inferior area $(\%)$} \\
\hline Hypokinesis & $21.4(n=66)$ \\
\hline Akinesis & $0.6(n=2)$ \\
\hline Dyskinesis & 0 \\
\hline Aneurysmal & 0 \\
\hline \multicolumn{2}{|c|}{ RWMA at lateral area (\%) } \\
\hline Hypokinesis & $20.1(n=62)$ \\
\hline Akinesis & 0 \\
\hline Dyskinesis & 0 \\
\hline Aneurysmal & 0 \\
\hline
\end{tabular}

$L V E F$ left ventricular ejection fraction, IVS-WT interventricular septal wall thickness, $P W T$ posterior wall thickness, $L V D d$ left ventricular enddiastolic diameter, $L V D$ s left ventricular systolic diameter, $E$ early diastolic filling velocity, $A$ atrial filling velocity, $e^{\prime}$ mitral annulus velocity consisting of the early diastolic phase, RWMA regional wall motion abnormality 
Table 3 Results of right cardiac catheterization and coronary angiography

\begin{tabular}{ll}
\hline Significant stenosis $(\%)$ & $10.7(n=33)$ \\
Right coronary artery & $17.2(n=53)$ \\
Left anterior descending artery & $11.4(n=35)$ \\
Left circumflex artery & $1.3(n=4)$ \\
Left main trunk & \\
Total occlusion $(\%)$ & $2.9(n=9)$ \\
Right coronary artery & $4.2(n=13)$ \\
Left anterior descending artery & $3.9(n=12)$ \\
Left circumflex artery & 0 \\
Left main trunk & \\
Results of the left cardiac pressure study $(\%)$ & $133.5 \pm 25.4$ \\
LVSP (mmHg) & $1.4 \pm 24.9$ \\
LVEDP $(\mathrm{mmHg})$ & $137.2 \pm 24.9$ \\
AoSP $(\mathrm{mmHg})$ & $65.0 \pm 12.1$ \\
AoDP $(\mathrm{mmHg})$ & $1571.5 \pm 408.9$ \\
Positive d $p / \mathrm{d} t(\mathrm{mmHg} / \mathrm{s})$ & $1506.2 \pm 408.2$ \\
Negative d $p / \mathrm{d} t(\mathrm{mmHg} / \mathrm{s})$ & $40.1 \pm 19.1$ \\
$\tau(\mathrm{ms})$ & \\
\hline
\end{tabular}

LVSP left ventricular systolic pressure, $L V E D P$ left ventricular enddiastolic pressure, AoSP systolic aortic pressure, $A o D P$ diastolic aortic pressure, Positive $d p / d t$ maximum rate of left ventricular pressure rise, Negative $d p / d t$ peak rate of fall in left ventricular pressure, $\tau$ isovolumetric relaxation time constant

between E/e'lat and LVEDP or $\tau$ of left ventricular diastolic performance parameters. Table 4 shows a comparison of the baseline parameters between patients with and without RWMAlat. The RWMAlat group tended to have low systolic performance, such as low LVEF, high brain natriuretic peptide levels, and enlarged left ventricular chambers. These differences might be a reflection of prior ischemic disease with RWMA.

\section{Discussion}

The present study confirmed that left ventricular diastolic performance, LVEDP and $\tau$, established by invasive techniques, correlate well with the E/e'lat, a non-invasive TDI parameter. However, the presence of RWMAlat on echocardiography weakened the correlation.

Assessing left ventricular diastolic performance is not only very important for the diagnosis of HFpEF, but also in that diastolic dysfunction contributes to heart failure with reduced systolic function. However, since "diastolic performance" is the product of a complex interaction of different factors in the diastolic phase, no unified parameter of diastolic performance can be established. Therefore, the non-invasive assessment of left ventricular diastolic performance is a far from easy task.
The European Society of Cardiology and the American College of Cardiology suggested a diagnostic strategy for $\mathrm{HFpEF}$ using $\mathrm{E} / \mathrm{e}^{\prime}$ as the non-invasive diagnostic parameter $[6,22]$, because it closely correlates with the left ventricular filling pressure [17, 37, 38]. Passive filling of inflows into the left ventricle is determined by left ventricular stiffness and compliance. The earliest finding of diastolic dysfunction appears as a decrement of the ratio of early diastolic filling velocity (E) to atrial filling velocity (A), reflecting a relaxation delay of the left ventricular muscle. With further progression of diastolic dysfunction, increased LVEDP becomes evident. In clinical studies, it is clear that E/e' correlates well with LVEDP [17, 19, 20, 39].

$\tau$, which is the time constant of the descending limb of the left ventricular pressure curve, is a standard parameter of left ventricular relaxation; relaxation disorders result in the prolongation of $\tau$. HFpEF patients with active relaxation disorders show prolonged $\tau$, and $\tau$ also correlates well with $\mathrm{E} / \mathrm{e}^{\prime}$ [20].

Parameters of left ventricular diastolic performance established invasively, such as LVEDP or $\tau$, and noninvasively measured $\mathrm{E} / \mathrm{e}^{\prime}$ are clearly assessed by different methodologies. Invasive parameters are obtained from the measurement of left ventricular pressure during isovolumetric relaxation or the rapid filling phase, whereas the E/ $\mathrm{e}^{\prime}$ ratio is obtained by measuring the mitral annular velocity during the rapid filling phase. These differences influence the correlation between invasive parameters and the value of $\mathrm{E} / \mathrm{e}^{\prime}$. It has been reported that various clinical features contribute to decreasing the strength of this correlation [19, 39]. Ommen et al. [17] pointed out that the correlation coefficient between E/ $\mathrm{e}^{\prime}$ and LVEDP varies depending on the LVEF. Another report suggested the possibility that underlying cardiac conditions influence the correlation between $\mathrm{E} / \mathrm{e}^{\prime}$ and LVEDP, recognized in differences between primary and secondary mitral regurgitation [24]. The correlation between $\mathrm{E} / \mathrm{e}^{\prime}$ and $\tau$ might be less stable under certain clinical conditions, but this remains controversial [17, 20, 40-42].

RWMA is regarded as one of the most influential factors contributing to the magnitude of $\mathrm{E} / \mathrm{e}^{\prime}$, because of the characteristics of the measurement methods. The present study showed that it is RWMAlat that worsens the correlation between invasive parameters and E/e'lat. We obtained values of $\mathrm{E} / \mathrm{e}^{\prime}$ using a method whereby $\mathrm{e}^{\prime}$ was measured from the early relaxation velocity of lateral mitral annulus in an apical 4-chamber view. It has been reported that $\mathrm{E} / \mathrm{e}^{\prime}$ measured at the septal mitral annulus correlates better with LVEDP or $\tau$ than when it is measured at the lateral mitral annulus [17]. On the other hand, one report suggested that E/e'lat correlates better with the LV filling pressure than when measured at the septal mitral annulus in cases with RWMA due to previous myocardial 
Fig. 1 Correlations between the $\mathrm{E} / \mathrm{e}^{\prime}$ ratio and 6 invasive parameters. The correlation coefficients between the tissue Doppler E/e' ratio and 6 invasive parameters obtained from left ventricular pressure assessments in all 308 patients are shown. Left ventricular enddiastolic pressure (LVEDP) and $\tau$ correlate well with the value of $\mathrm{E} / \mathrm{e}^{\prime}$
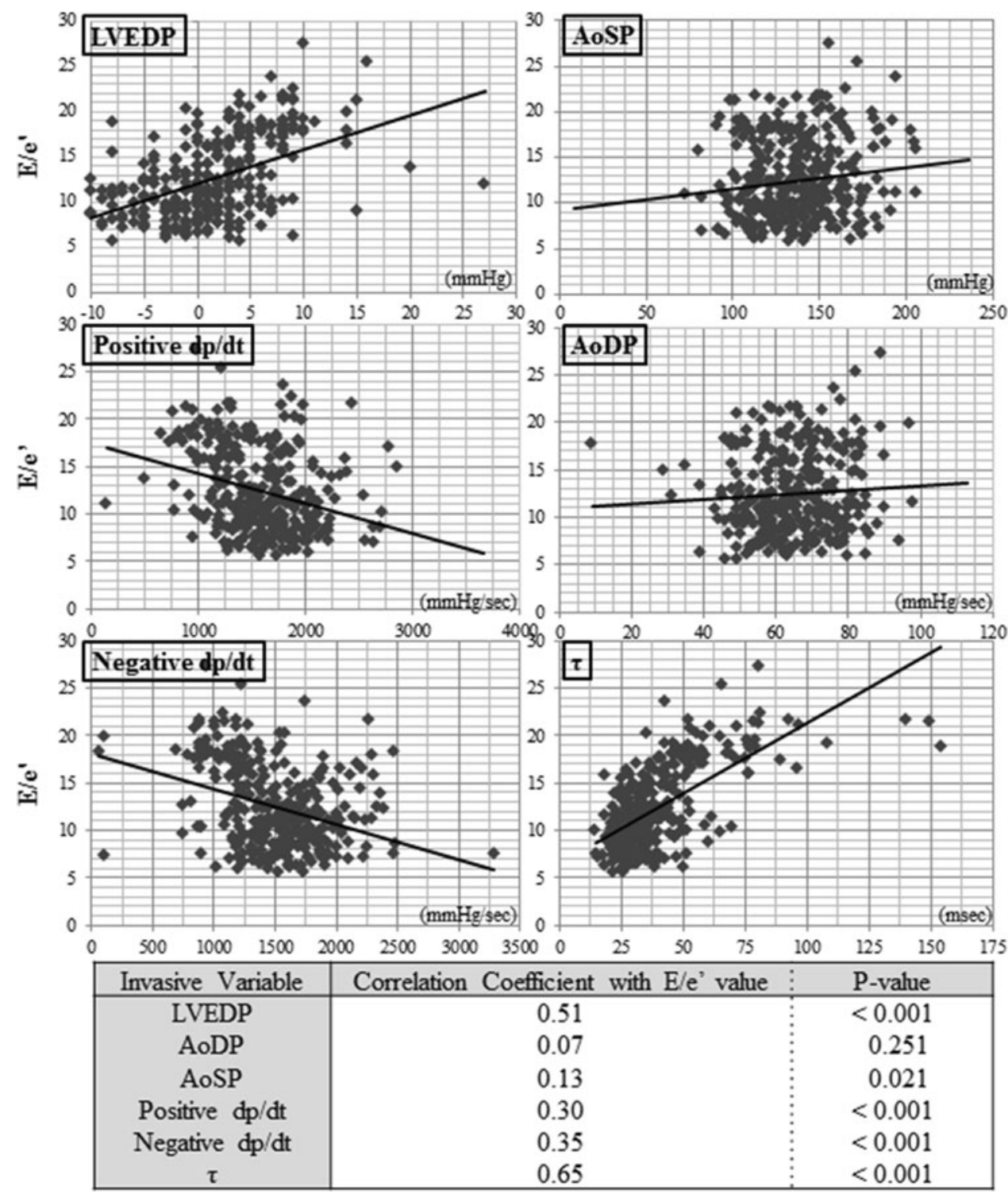

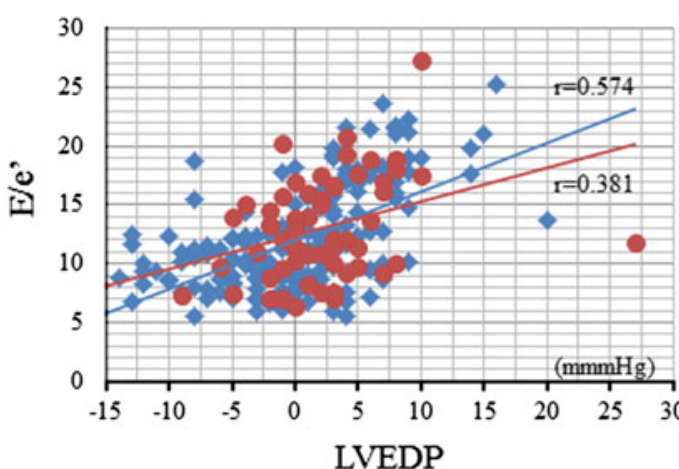

Fig. 2 The correlation coefficients between the $\mathrm{E} / \mathrm{e}^{\prime}$ ratio and invasive parameters are influenced by regional wall motion abnormality at the lateral wall. The effect of regional wall motion abnormality at the lateral wall (RWMAlat) on the strength of the correlation between $\mathrm{E} / \mathrm{e}^{\prime}$ and invasive parameters, as seen by the

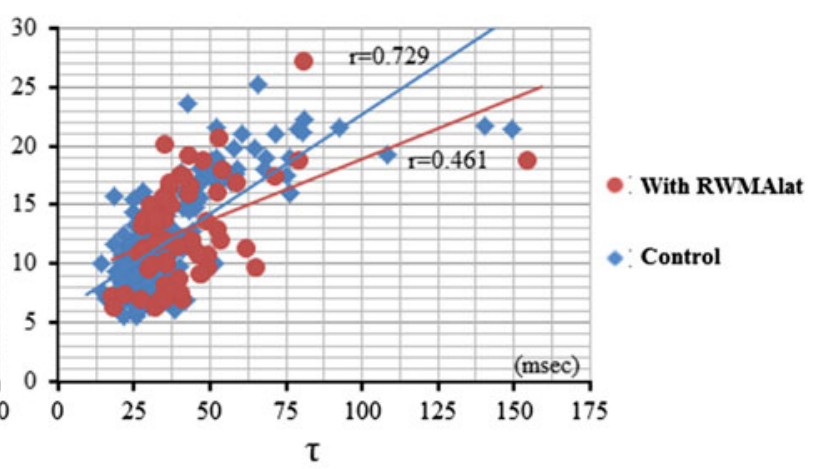

comparison with a control group without RWMAlat, is shown. The E/ $\mathrm{e}^{\prime}$ ratio and LVEDP correlation coefficient of the group with RWMAlat was 0.381 compared to 0.574 for controls with RWMA (left panel). Similarly, the E/ $\mathrm{e}^{\prime}$ ration and $\tau$ correlation coefficient decreased from 0.729 to 0.461 (right panel) 
Table 4 Comparison of baseline parameters between patients with and without RWMAlat

\begin{tabular}{|c|c|c|c|}
\hline & $\begin{array}{l}\text { RWMAlat } \\
(n=62)\end{array}$ & $\begin{array}{l}\text { Without RWMAlat } \\
(n=246)\end{array}$ & $P$ value \\
\hline Age (years) & $62.2 \pm 12.6$ & $64.6 \pm 10.5$ & 0.1245 \\
\hline Male $(\%)$ & $83.9(n=52)$ & $82.5(n=203)$ & 0.8012 \\
\hline Height $(\mathrm{cm})$ & $163.5 \pm 7.8$ & $162.3 \pm 9.3$ & 0.3345 \\
\hline Weight (kg) & $62.5 \pm 12.3$ & $63.0 \pm 11.3$ & 0.7294 \\
\hline $\begin{array}{l}\text { Body surface } \\
\text { area }\left(\mathrm{m}^{2}\right)\end{array}$ & $1.67 \pm 0.18$ & $1.67 \pm 0.18$ & 0.9242 \\
\hline $\begin{array}{l}\text { Serum creatinine } \\
(\mathrm{mg} / \mathrm{dl})\end{array}$ & $1.38 \pm 1.75$ & $1.47 \pm 1.92$ & 0.7332 \\
\hline $\begin{array}{l}\text { Estimated GFR } \\
(\mathrm{ml} / \mathrm{min})\end{array}$ & $60.7 \pm 22.6$ & $61.3 \pm 23.2$ & 0.8544 \\
\hline $\mathrm{BNP}(\mathrm{pg} / \mathrm{ml})$ & $138.1 \pm 170.3$ & $85.3 \pm 184.6$ & 0.0476 \\
\hline $\begin{array}{l}\text { Diabetes mellitus } \\
(\%)\end{array}$ & $37.1(n=23)$ & $36.2(n=89)$ & 0.8932 \\
\hline Hypertension (\%) & $74.2(n=46)$ & $74.8(n=184)$ & 0.9222 \\
\hline Dyslipidemia (\%) & $61.3(n=38)$ & $66.7(n=164)$ & 0.4258 \\
\hline $\begin{array}{l}\text { Total cholesterol } \\
(\mathrm{mg} / \mathrm{dl})\end{array}$ & $174.2 \pm 34.7$ & $179.3 \pm 42.8$ & 0.3869 \\
\hline $\begin{array}{l}\text { Triglyceride (mg/ } \\
\text { dl) }\end{array}$ & $120.0 \pm 68.5$ & $150.6 \pm 147.7$ & 0.1144 \\
\hline $\operatorname{LVEF}(\%)$ & $50.3 \pm 11.0$ & $65.8 \pm 10.6$ & $<0.001$ \\
\hline IVS-WT (mm) & $11.2 \pm 2.1$ & $11.0 \pm 2.1$ & 0.6079 \\
\hline PWT-WT (mm) & $9.8 \pm 2.4$ & $10.4 \pm 1.7$ & 0.0335 \\
\hline LVDd $(\mathrm{mm})$ & $54.6 \pm 7.5$ & $49.1 \pm 6.4$ & $<0.001$ \\
\hline LVDs (mm) & $39.4 \pm 9.4$ & $29.7 \pm 6.3$ & $<0.001$ \\
\hline $\mathrm{E}(\mathrm{m} / \mathrm{s})$ & $53.2 \pm 21.3$ & $57.3 \pm 17.6$ & 0.1191 \\
\hline $\mathrm{A}(\mathrm{m} / \mathrm{s})$ & $65.4 \pm 21.7$ & $71.6 \pm 17.8$ & 0.0215 \\
\hline $\mathrm{E} / \mathrm{A}$ & $0.85 \pm 0.3$ & $0.83 \pm 0.3$ & 0.5909 \\
\hline $\mathrm{e}^{\prime}(\mathrm{cm} / \mathrm{s})$ & $4.6 \pm 2.3$ & $5.1 \pm 2.1$ & 0.0801 \\
\hline $\mathrm{E} / \mathrm{e}^{\prime}$ & $12.9 \pm 4.4$ & $12.3 \pm 4.4$ & 0.3754 \\
\hline LVEDP (mmHg) & $1.85 \pm 5.8$ & $0.86 \pm 5.9$ & 0.3257 \\
\hline$\tau(\mathrm{ms})$ & $42.3 \pm 19.3$ & $39.5 \pm 19.1$ & 0.3122 \\
\hline
\end{tabular}

$G F R$ glomerular filtration rate, $B N P$ brain natriuretic peptide, $L V E F$ left ventricular ejection fraction, IVS-WT interventricular septal wall thickness, $P W T$ posterior wall thickness, $L V D d$ left ventricular enddiastolic diameter, $L V D$ s left ventricular systolic diameter, $E$ early diastolic filling velocity, $A$ atrial filling velocity, $e^{\prime}$ mitral annulus velocity consisting of the early diastolic phase, LVEDP left ventricular end-diastolic pressure, $\tau$ isovolumetric relaxation time constant

infarction [43]. These investigators recommended using E/e'lat in cases with RWMA. However, RWMAlat would be expected to have no small impact on the magnitude of E/e'lat, which we confirmed using the correlation with the invasive parameters LVEDP and $\tau$. Our data suggest that the diagnostic value of $\mathrm{E} / \mathrm{e}^{\prime}$ lat for $\mathrm{HFpEF}$ is lower in patients with RWMAlat than those without. RWMA may, thus, decrease the accuracy of $\mathrm{E} / \mathrm{e}^{\prime}$ for the diagnosis of HFpEF. We emphasize the necessity of using two E/e measurement methods (between the lateral and septal wall) depending on the clinical situation. At least in cases with
RWMAlat, our data suggest that E/e'lat has low diagnostic value in the prediction of left ventricular diastolic performance. If the dissociation between lateral and septal value is shown, the value measured at the site without RWMA has higher credibility.

There are major limitations to this retrospective study. First, fluid-filled pigtail catheters were used in the pressure measurements, even though they are inferior in frequency response characteristics to a pressure-conductance catheter. Using the latter might result in better correlations of invasive parameters with $\mathrm{E} / \mathrm{e}^{\prime}$. The time interval between echocardiographic assessment and invasive measurement is also a major concern. Moreover, the RWMAlat group tended to have lower systolic function, so it cannot be excluded that differences in baseline characteristics contribute to the weaker correlation in patients with RWMAlat.

Significant mitral regurgitation has a possibility to impact on the magnitude of $\mathrm{E} / \mathrm{e}^{\prime}$. Though the present study included only one case $(0.3 \%)$ with severe mitral regurgitation, this impact on our outcome is thought to be small.

The left ventricular filling pressure or average left atrium pressure were not evaluated as invasive parameters of diastolic performance. These parameters might contribute to provide stronger evidence.

In conclusion, the E/e'lat ratio obtained by TDI is well correlated with parameters of left ventricular diastolic performance obtained by invasive techniques. However, E/e'lat might not reflect diastolic performance accurately in cases with RWMAlat. A careful assessment of E/ $e^{\prime}$ lat is required in such patients for the prediction of diastolic performance.

Conflict of interest All authors have no conflicts of interest with companies or other organizations.

Open Access This article is distributed under the terms of the Creative Commons Attribution License which permits any use, distribution, and reproduction in any medium, provided the original author(s) and the source are credited.

\section{References}

1. Kitzman DW, Higginbotham MB, Cobb FR, et al. Exercise intolerance in patients with heart failure and preserved left ventricular systolic function: failure of the frank-starling mechanism. J Am Coll Cardiol. 1991;17:1065-72.

2. Vasan RS, Larson MG, Benjamin EJ, et al. Congestive heart failure in subjects with normal versus reduced left ventricular ejection fraction: prevalence and mortality in a population-based cohort. J Am Coll Cardiol. 1999;33:1948-55.

3. Vasan RS, Levy D. Defining diastolic heart failure: a call for standardized diagnostic criteria. Circulation. 2000;101:2118-21.

4. Gandhi SK, Powers JC, Nomeir AM, et al. The pathogenesis of acute pulmonary edema associated with hypertension. $\mathrm{N}$ Engl J Med. 2001;344:17-22. 
5. Hunt SA, Abraham WT, Chin MH, et al. ACC/AHA 2005 Guideline Update for the Diagnosis and Management of Chronic Heart Failure in the Adult: a report of the American College of Cardiology/American Heart Association Task Force on Practice Guidelines (Writing Committee to Update the 2001 Guidelines for the Evaluation and Management of Heart Failure): developed in collaboration with the American College of Chest Physicians and the International Society for Heart and Lung Transplantation: endorsed by the Heart Rhythm Society. Circulation. 2005; 112(12):e154-235.

6. Paulus WJ, Tschöpe C, Sanderson JE, et al. How to diagnose diastolic heart failure: a consensus statement on the diagnosis of heart failure with normal left ventricular ejection fraction by the Heart Failure and Echocardiography Associations of the European Society of Cardiology. Eur Heart J. 2007;28:2539-50.

7. Hogg K, Swedberg K, McMurray J. Heart failure with preserved left ventricular systolic function; epidemiology, clinical characteristics, and prognosis. J Am Coll Cardiol. 2004;43:317-27.

8. Owan TE, Hodge DO, Herges RM, et al. Trends in prevalence and outcome of heart failure with preserved ejection fraction. N Engl J Med. 2006;355:251-9.

9. Tsuchihashi-Makaya M, Hamaguchi S, Kinugawa S, et al. Characteristics and outcomes of hospitalized patients with heart failure and reduced vs preserved ejection fraction. Report from the Japanese Cardiac Registry of Heart Failure in Cardiology (JCARE-CARD). Circ J. 2009;73:1893-900.

10. Nagueh SF, Middleton KJ, Kopelen HA, et al. Doppler tissue imaging: a noninvasive technique for evaluation of left ventricular relaxation and estimation of filling pressures. J Am Coll Cardiol. 1997;30:1527-33.

11. Nagueh SF, Mikati I, Kopelen HA, et al. Doppler estimation of left ventricular filling pressure in sinus tachycardia. A new application of tissue Doppler imaging. Circulation. 1998;98:1644-50.

12. Okura H, Takada Y, Kubo T, et al. Tissue Doppler-derived index of left ventricular filling pressure, $\mathrm{E} / \mathrm{E}^{\prime}$, predicts survival of patients with non-valvular atrial fibrillation. Heart. 2006;92:1248-52.

13. Little WC, Oh JK. Echocardiographic evaluation of diastolic function can be used to guide clinical care. Circulation. 2009;120:802-9.

14. Oh JK, Hatle L, Tajik AJ, et al. Diastolic heart failure can be diagnosed by comprehensive two-dimensional and Doppler echocardiography. J Am Coll Cardiol. 2006;47:500-6.

15. Solomon SD, Stevenson LW. Recalibrating the barometer: is it time to take a critical look at noninvasive approaches to measuring filling pressures? Circulation. 2009;119:13-5.

16. Yellin EL, Nikolic S, Frater RW. Left ventricular filling dynamics and diastolic function. Prog Cardiovasc Dis. 1990;32:247-71.

17. Ommen SR, Nishimura RA, Appleton CP, et al. Clinical utility of Doppler echocardiography and tissue Doppler imaging in the estimation of left ventricular filling pressures: a comparative simultaneous Doppler-catheterization study. Circulation. 2000;102:1788-94.

18. Maurer MS, Spevack D, Burkhoff D, et al. Diastolic dysfunction: can it be diagnosed by Doppler echocardiography? J Am Coll Cardiol. 2004;44:1543-9.

19. Bruch C, Grude M, Müller J, et al. Usefulness of tissue Doppler imaging for estimation of left ventricular filling pressures in patients with systolic and diastolic heart failure. Am J Cardiol. 2005;95:892-5.

20. Kasner M, Westermann D, Steendijk P, et al. Utility of Doppler echocardiography and tissue Doppler imaging in the estimation of diastolic function in heart failure with normal ejection fraction: a comparative Doppler-conductance catheterization study. Circulation. 2007;116:637-47.

21. Dickstein K, Cohen-Solal A, Filippatos G, et al. ESC Guidelines for the diagnosis and treatment of acute and chronic heart failure 2008: the Task Force for the Diagnosis and Treatment of Acute and Chronic Heart Failure 2008 of the European Society of Cardiology. Developed in collaboration with the Heart Failure Association of the ESC (HFA) and endorsed by the European Society of Intensive Care Medicine (ESICM). Eur Heart J. 2008;29:2388-442.

22. Maeder MT, Kaye DM. Heart failure with normal left ventricular ejection fraction. J Am Coll Cardiol. 2009;53:905-18.

23. Nagueh SF, Appleton CP, Gillebert TC, et al. Recommendations for the evaluation of left ventricular diastolic function by echocardiography. J Am Soc Echocardiogr. 2009;22:107-33.

24. Bruch C, Stypmann J, Gradaus R, et al. Usefulness of tissue Doppler imaging for estimation of filling pressures in patients with primary or secondary pure mitral regurgitation. Am J Cardiol. 2004;93:324-8.

25. Lang RM, Bierig M, Devereux RB, et al. Recommendations for chamber quantification: a report from the American Society of Echocardiography's Guidelines and Standards Committee and the Chamber Quantification Writing Group, developed in conjunction with the European Association of Echocardiography, a branch of the European Society of Cardiology. J Am Soc Echocardiogr. 2005; 18:1440-63.

26. Schiller NB, Acquatella H, Ports TA, et al. Left ventricular volume from paired biplane two-dimensional echocardiography. Circulation. 1979;60:547-55.

27. Quiñones MA, Otto CM, Stoddard M, et al. Recommendations for quantification of Doppler echocardiography: a report from the Doppler Quantification Task Force of the Nomenclature and Standards Committee of the American Society of Echocardiography. J Am Soc Echocardiogr. 2002;15:167-84.

28. Zoghbi WA, Enriquez-Sarano M, Foster E, et al. Recommendations for evaluation of the severity of native valvular regurgitation with two-dimensional and Doppler echocardiography. J Am Soc Echocardiogr. 2003;16:777-802.

29. Bonow RO, Carabello BA, Kanu C, et al. ACC/AHA 2006 guidelines for the management of patients with valvular heart disease: a report of the American College of Cardiology/American Heart Association Task Force on Practice Guidelines (writing committee to revise the 1998 Guidelines for the Management of Patients With Valvular Heart Disease): developed in collaboration with the Society of Cardiovascular Anesthesiologists: endorsed by the Society for Cardiovascular Angiography and Interventions and the Society of Thoracic Surgeons. Circulation. 2006;114:e84-231.

30. Austen WG, Edwards JE, Frye RL, et al. A reporting system on patients evaluated for coronary artery disease. Report of the Ad Hoc Committee for Grading of Coronary Artery Disease, Council on Cardiovascular Surgery, American Heart Association. Circulation. 1975;51:5-40.

31. Weiss JL, Frederiksen JW, Weisfeldt ML. Hemodynamic determinants of the time-course of fall in canine left ventricular pressure. J Clin Invest. 1976;58:751-60.

32. Weisfeldt ML, Frederiksen JW, Yin FC, et al. Evidence of incomplete left ventricular relaxation in the dog: prediction from the time constant for isovolumic pressure fall. J Clin Invest. 1978;62:1296-302.

33. Hirota Y. A clinical study of left ventricular relaxation. Circulation. 1980;62:756-63.

34. Pagel PS, Hettrick DA, Kersten JR, et al. Isoflurane and halothane do not alter the enhanced afterload sensitivity of left ventricular 
relaxation in dogs with pacing-induced cardiomyopathy. Anesthesiology. 1997;87:952-62.

35. Graham MR, Thiessen DB, Mutch WA. Left ventricular systolic and diastolic function is unaltered during propofol infusion in newborn swine. Anesth Analg. 1998;86:717-23.

36. De Hert SG, ten Broecke PW, Mertens E, et al. Sevoflurane but not propofol preserves myocardial function in coronary surgery patients. Anesthesiology. 2002;97:42-9.

37. Hillis GS, Møller JE, Pellikka PA, et al. Noninvasive estimation of left ventricular filling pressure by $\mathrm{E} / \mathrm{e}^{\prime}$ is a powerful predictor of survival after acute myocardial infarction. J Am Coll Cardiol. 2004;43:360-7.

38. Dokainish H, Zoghbi WA, Lakkis NM, et al. Optimal noninvasive assessment of left ventricular filling pressures: a comparison of tissue Doppler echocardiography and B-type natriuretic peptide in patients with pulmonary artery catheters. Circulation. 2004;109:2432-9.
39. Burgess MI, Jenkins C, Sharman JE, et al. Diastolic stress echocardiography: hemodynamic validation and clinical significance of estimation of ventricular filling pressure with exercise. J Am Coll Cardiol. 2006;47:1891-900.

40. Sohn DW, Chai IH, Lee DJ, et al. Assessment of mitral annulus velocity by Doppler tissue imaging in the evaluation of left ventricular diastolic function. $\mathrm{J}$ Am Coll Cardiol. 1997;30:474-80.

41. Ohte N, Narita H, Hashimoto T, et al. Evaluation of left ventricular early diastolic performance by color tissue Doppler imaging of the mitral annulus. Am J Cardiol. 1998;82:1414-7.

42. Nagueh SF, Sun H, Kopelen HA, et al. Hemodynamic determinants of the mitral annulus diastolic velocities by tissue Doppler. J Am Coll Cardiol. 2001;37:278-85.

43. Lim HS, Kang SJ, Choi JH, et al. Is $\mathrm{E} / \mathrm{E}^{\prime}$ reliable in patients with regional wall motion abnormalities to estimate left ventricular filling pressure? Int J Cardiovasc Imaging. 2009;25:33-9. 